\title{
The prediction of structural fractures in coal seams of the Kuba coalfield, China: an application for coalbed methane (CBM) recovery development
}

\author{
Zhou Zhang ${ }^{1,2,3}$, Min Zhou ${ }^{1}$, Yun-Xing Cao ${ }^{1,2,3}$, Bao-An Xian ${ }^{1,2,3}$ and Di Gao ${ }^{1,2, *}$ \\ ${ }^{1}$ School of Resources and Environment, Henan Polytechnic University, Jiaozuo, China; ( ${ }^{*}$ corresponding author: gaodi@hpu.edu.cn) \\ ${ }^{2}$ Collaborative Innovation Center of Coalbed Methane and Shale Gas for Central Plains Economic Region, Henan Province, Jiaozuo, China \\ ${ }^{3}$ Henan International Joint Laboratory for Unconventional Energy Geology and Development, Jiaozuo, China
}

doi: $10.4154 / g c .2019 .26$

Article history:

Manuscript received February 01, 2019

Revised manuscript accepted August 28, 2019

Available online December 20, 2019

\begin{abstract}
The structural fracture system in a coal reservoir enables coalbed methane (CBM) percolation and migration. It plays an important role in CBM exploration and exploitation (recovery) development. Nearly vertical strata with Mesozoic bituminous coal seams in the central part of the Kuba coalfield of the Xinjiang Province in China were studied using large-scale mapping of the structural fractures on the surface, and a using a technique for comparing and analyzing sections of the underground coal mine. This investigation verified that similar structural fractures are developed in the underground coal seams as those on the surface, and surrounding rocks represent the same tectonic layer. Meanwhile, a corresponding relationship between the characteristics of the development of fractures - including the growth directions and degree of development of fractures in coal seams and the surrounding rocks - was established. Based on this, the research presents a new method for predicting a pattern of fractures in coal seams and the coal structure, respectively. Finally, the study area was divided into zones with dense, moderate and un-developed fractures. The method should be applicable in various coal-and-gas engineering fields, for example the prediction of fractured zones in coal seams, the prediction of coal structure, and for projecting the well arrangement in the exploration and development of economic recovery of CBM.
\end{abstract}

Keywords: coal seams and surrounding rocks, Mesozoic bituminous coal, structural fracture system, corresponding relations, coalbed methane (CBM), Kuba coalfield, China observational and geophysical data of a few samples cannot reflect the development characteristics of the fracture system in the coal seams of the whole development zone. The fracture system in a coal seam is composed of pores, microcracks, endogenous fractures (face cleats and butt cleats) and structural fractures, in which the pore diameter is of nannometre dimensions, the length of microfractures is of micrometre dimensions, the length of endogenous fractures (face cleats and butt cleats) is of centimetre dimensions, and the structural fractures range to metre dimensions and more. In the whole fracture system, the structural fracture is the main channel of coalbed methane migration and the main contributor of its permeability.

It is known that tectonic stress is the primary reason for the generation of fractures in coal seams and their surrounding rocks, while the joint influences of lithology, stratum thickness and tectonic stress affect the degree of fracture development (MCKEE et al., 1988; SOLANO-ACOSTA et al., 2007; DATTA, 2016). Within the coal, the fracture (cleat) system is also dependant on coal rank (BROOK et al., 2016; WENIGER et al., 2016; BUSSE et al., 2017) lithotype composition and mineral admixtures (DAWSON \& ESTERLE, 2010; WIDERA, 2014).

As to the area where joints are densely developed in the outcrop strata at the surface, the joints in the same area in the strata deep underground are usually more compact than those in the strata of adjacent regions (WHEELER, 1980; CHEN et al., 2017; $\mathrm{ZHAO}$ et al., 2019). That is to say that under the influence of tectonic stress, the fractures generated in strata with different lithologies, thicknesses, and tectonic positions closely correspond However, due to a high degree of heterogeneity in coal seams, the condly, research methods are limited. Existing studies on fractu systems mainly observe pores and fractures by sampling hand specimens or rock and coal cores from boreholes or distinguish and predict coal fractures utilizing geophysical methods or mathe-
matical simulation (YAO et al., 2009; KORONCZ et al., 2017). 
(LAUBACH et al., 1998; RAWNSLEY et al., 1998; BAI \& POLLARD, 2000; ARLEGUI \& SIMÓN, 2001). Therefore, the development degree of the underground coal seam fractures can be predicted by investigating the development degree of fractures in the outcropped strata at the surface. Based on this understanding, a new method of structural fracture study can be used to evaluate the coalbed methane exploration development zone at the surface.

The large-scale mapping of structural fractures and the fine comparison and analysis of the underground coal seams were performed on the CBM development zone of the Kuba coalfield in Xinjiang, China. In this process, parameters including the development characteristics of the fracture systems, the predominant development directions and the linear density of the fractures at the ground surface, the underground coal seams, and the surrounding rocks were acquired and compared. Meanwhile, the corresponding relationship between the fractures in the coal seams and the surrounding rocks was established with the aim of applying the knowledge to the exploration and development of the CBM, especially to predict the development degree of the fractures and the coal's structure in underground coal seams.

\section{GEOLOGICAL SETTING}

The Kuba coalfield of Xinjiang, China is located in the southern foothills of the Tianshan fold belt (Fig. 1). In terms of the regional tectonic setting, the Kuba coalfield ispart of the Kuba depression. It is located in the northern monoclinal zone of the Kuba depression and bears the same tectonic deformation as the whole Kuba depression (LIANG et al., 2003; FENG et al., 2018; LAI et al., 2019).

The Mesozoic strata of the Kuba coalfield have undergone five stages of palaeotectonic stress, as its coal-bearing strata are the lower series of the Jurassic system. These five tectonic phases form the present tectonic framework, including the early and late Yanshanian, and early, middle and late Himalayan. The average maximum principal compressive stress direction of the early Yanshanian tectonic stress field is about $310^{\circ}$, while that of the late Yanshanian tectonic stress field is about $0^{\circ}$ and the average maximum palaeo-effective stress value is $39.3 \mathrm{MPa}$. In the early Himalayan period, the tectonic stress field was compressed in a nearly N-S direction. During this period, the average horizontal maximum principal compressive stress direction was about $350^{\circ}$, and the average maximum palaeo-effective stress value was 55.7 $\mathrm{MPa}$. The maximum principal compressive stress direction in the middle Himalaya is nearly north-south, and the average maximum palaeo-effective stress value is $63.6 \mathrm{MPa}$ during this period. The maximum principal compressive stress direction of the late Himalayan tectonic stress field is nearly N-S horizontal compression, and the average maximum palaeo-effective stress value is 79.4 MPa, which indicates that the late Himalayan tectonic stress
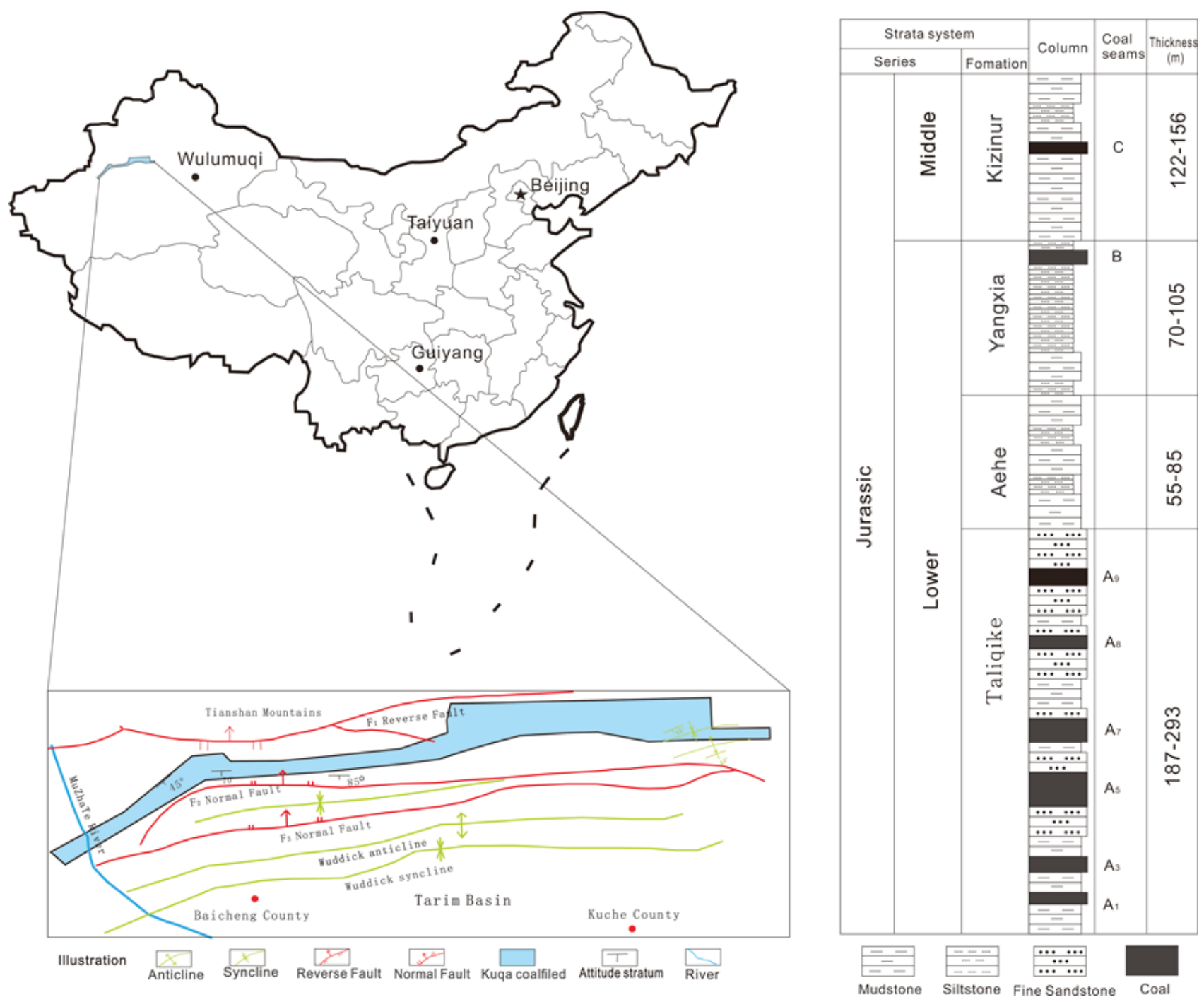

Figure 1. Location of the study area and stratigraphic column of the Jurassic coal-bearing strata. 

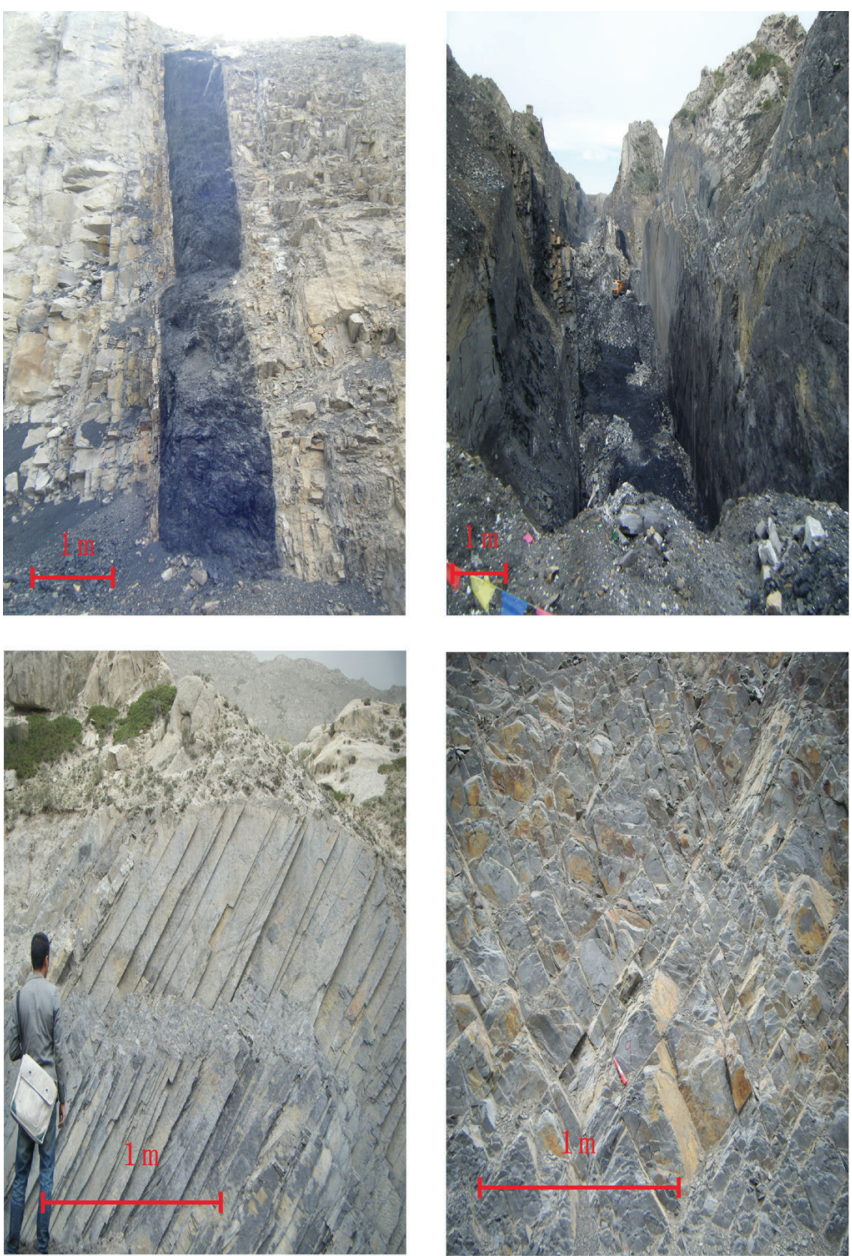
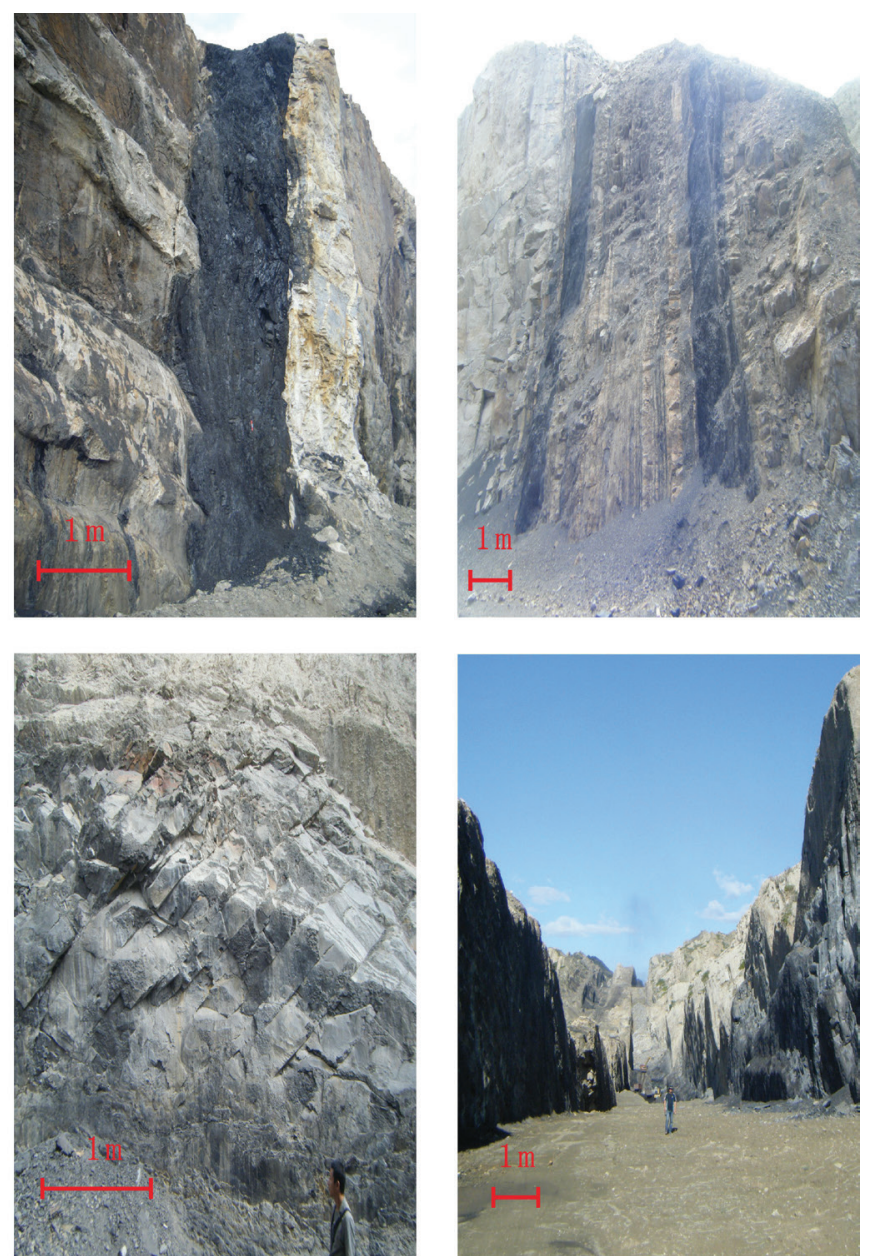

Figure 2. Outcrop of coal and surrounding rock in the field.

field was the most intense compressional period in the Kuba Depression, and finally forms a nearly E-W thrusting knappe tectonic framework in this area. Except for the early Yanshanian, when the maximum principal stress was in a NW-SE direction, other stages were a result of maximum principal stress in a nearly $\mathrm{N}-\mathrm{S}$ direction. Under the stress of several stages, many similar and closely related fractures were generated within the surrounding rocks and the coal seam reservoirs (RAWNSLEY et al., 1998; ARLEGUI \& SIMÓN, 2001).

The middle part of the coalfield is a monocline structure inclined towards the south. The strata trend nearly EW trended. The tendency of strata is $78^{\circ}$ to $184^{\circ}$, and local strata are inverted. The dip angle ranges from $80^{\circ}$ to $89^{\circ}$, and the strata are nearly vertical. The coal-bearing strata in this region belong to the Taliqike formation of the lower Jurassic series $\left(\mathrm{J}_{1} \mathrm{t}\right)$ and are mainly composed of glutenites (massive sandstones and conglomerates), gritstones (coarse- and angular-grained siliceous sandstones), medium- and fine-grained sandstones, siltstones, mudstones, and coal seams. Affected by multiple stages of tectonic stress, fractures are well developed in these strata.

Limited by natural conditions, the development of the fractures in coal seams and surrounding rocks cannot be observed directly in ordinary CBM development zones. However, the nearly vertical coal seams and the well-preserved coal seam outcrops at the surface of the mining area provide excellent conditions for observing and analyzing the corresponding relationships between the fracture systems in coal seams and surrounding rocks (Fig. 2).

\section{RESEARCH METHODS}

\subsection{The high-precision structural fracture mapping technique}

In this study, a high-precision structural mapping technique was used with special emphasis on studying the fracture system. At the surface, the spacing of the observation points ranged from $100-150 \mathrm{~m}$, and the density of the observation points was approximately 100 per square kilometre. The reference standard was "Coalfield Geological Mapping Regulations" (THE MINISTRY OF LAND AND MINERAL RESOURCES OF THE PR OF CHINA, 2014). In addition, there are coal mines under exploitation in the study area, which were convenient for the observation of fracture systems in the underground coal strata. In the 3515 horizontal roadway of the spacing, the observation points ranged from 1-10 $\mathrm{m}$ on the coal wall. Working faces are excavated manually in the Kuba coal mines. A fine anatomical comparison technique was used to study the internal and external fractures in the underground coal reservoir (Figure 3).

Using surface high-precision structural fracture mapping in the CBM development block of the Kuba coalfield, the macrogeometric parameters of joint fractures of the surrounding rocks were studied including (1) Dip angle; (2) Direction; (3) Cutting relationships; (4) Combination form; (5) Scale; and (6) Filling degree. 


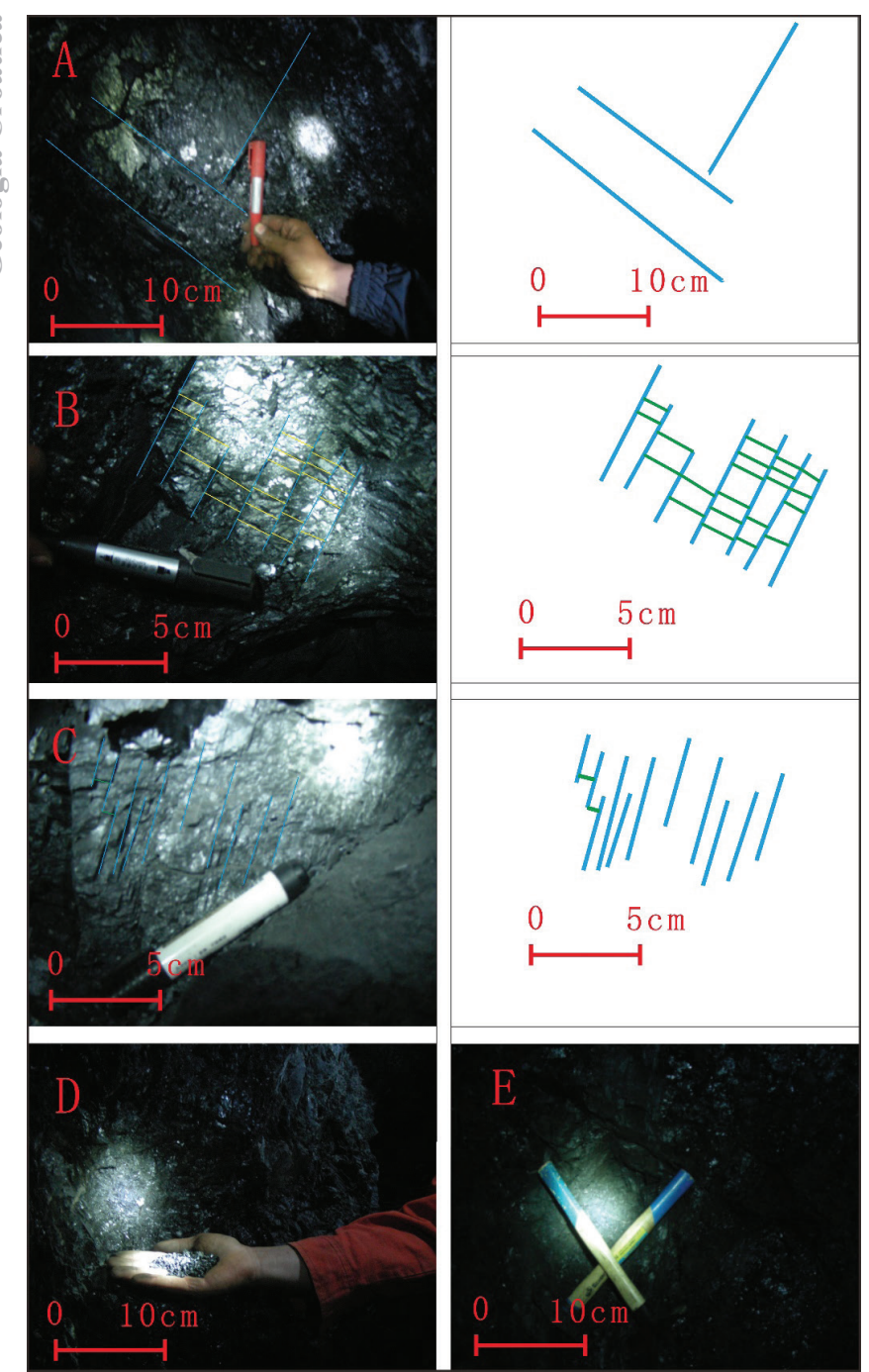

Figure 3. Coal reservoir in underground coal mine.

A - Development of two groups of structural fractures in coal seams B - Development of two groups of endogenous fractures in coal seams C - Development of one group of endogenous fractures in coal seams D and E - Fragmentation of coal structure in coal seams

\subsection{The fine observation and dissection technique of underground coal reservoirs}

Fine observation and dissection of coal reservoirs in the surface and underground were performed. This technique is mainly used to observe and dissect the structural fractures of a coal reservoir in a coal mine roadway. The observations ranged from about every 10 metres to tens of metres. The direction, density, and filling of structural fractures were observed in detail, and samples of coal and rock were collected to be tested in the laboratory. Based on this, three major characteristics most closely related to the coal reservoirs were observed including: (1) the spatial distribution characteristics of the studied coal reservoir; (2) the structural characteristics of the coal; and (3) the physical characteristics of the rocks. The development characteristics of fractures in the coal reservoirs were studied at both macroscopic and microscopic scales.

\subsection{Micromorphological observations}

In order to describe the shape, length, aperture, and connectivity of micro-fractures coal and rock samples were studied using following procedures (KARACAN \& OKANDAN, 2000): opti- cal microscopy (LV100 POL microscope with an MPS 60 photometer system), and scanning electron microscopy (FEI QUANTA 250 SEM) equipped with a high performance X-ray energy spectrometer that simultaneously carried out qualitative and semi-quantitative analysis of the elements of the surface layer of each sample to provide a comprehensive analysis of morphology and the chemical composition. The coal samples were divided into two groups of coal slices, and the processes were conducted as follows. The first group (for optical microscopy) was incised and polished to $30 \times 30 \mathrm{~mm}$ cubes, of which the surface was divided into 9 equal zones of $10 \times 10 \mathrm{~mm}$ used to determine the fracture amount and type in a sequence. In the second group (for the SEM), one side of the polished coal sample surface was gold-plated to increase the electrical conductivity.

In order to observe the microscopic fracture system in coal, samples of the $A_{1}, A_{3}, A_{5}, A_{7}, A_{8}$, and $A_{9}$ coals were collected. The development of microfractures is restricted by the internal components of the coals which are predominantly detrovitrinite and telovitrinite (after the ICCP, 1998 classification) plus mineral admixtures. Development of microfractures usually occurs in matrix vitrinite (detrovitrinite) and homogenous vitrinite (telovitrinite). When observed under a microscope, microfractures in the $A_{1}$ coal sample were only weakly developed, and microfractures were mostly filled with inorganic minerals. The microfractures extended $1 \times 10^{4}-1 \times 10^{7} \mathrm{~nm}$, and the width was approximately $1 \times 10^{3}-1 \times 10^{4} \mathrm{~nm}$. The connectivity between the matrix pores and fracture system was not good, which is unfavourable for the development of coalbed gas migration. The $\mathrm{A}_{3}$ coal microfractures had good connectivity between the matrix pores and fracture system. Powder was readily produced where microfractures developed, especially in the intersections of microfractures in different directions, and the coalbed methane migration pathway was easily blocked by the coal powder. Additionally, the cutting phenomenon of microcracks could be seen. The microfractures of $\mathrm{A}_{5}$ coal were not developed, the connectivity between the matrix pores and fracture system was good, powder production was low in the microfractures, and pyrite occasionally filled microfractures. The $\mathrm{A}_{7}$ coal microfractures were less developed, and the connectivity was not good; the microfractures were mostly filled with calcite. The $A_{8}$ and $A_{9}$ coal microfractures were less developed, and the matrix pores and fracture system were well connected, which is favourable for the migration of coalbed methane. The microfractures clearly showed cutting and dislocations, Some microfractures were filled with vein quartz (Figure 4).

\section{RESULTS AND DISCUSSION}

\subsection{Tectonic fracture occurrence}

The exogenic fractures are generated due to the exogenic tectonic stress, which acts in the same way to the formation of the joint fractures in both the surrounding rocks and the coal. That is, when the stress is greater than the ultimate strengths of the surrounding rocks and coal, fractures are generated. In the research area, shear fractures are mainly developed. The development morphology of the exogenic fractures in coal and the joints in the surrounding rocks are similar, so the jointed surrounding rocks were taken here to analyze the force conditions of the exogenic fractures. The study shows that the shear fractures develop along a surface in the surrounding rocks, which is not only related to the intensity of the shear stress at the surface, but also to the normal stress of the surface. The rocks are unlikely to fracture along the acting surfaces of the maximum shear stress but rather along the surface where the resultant force of the shear stress and the 

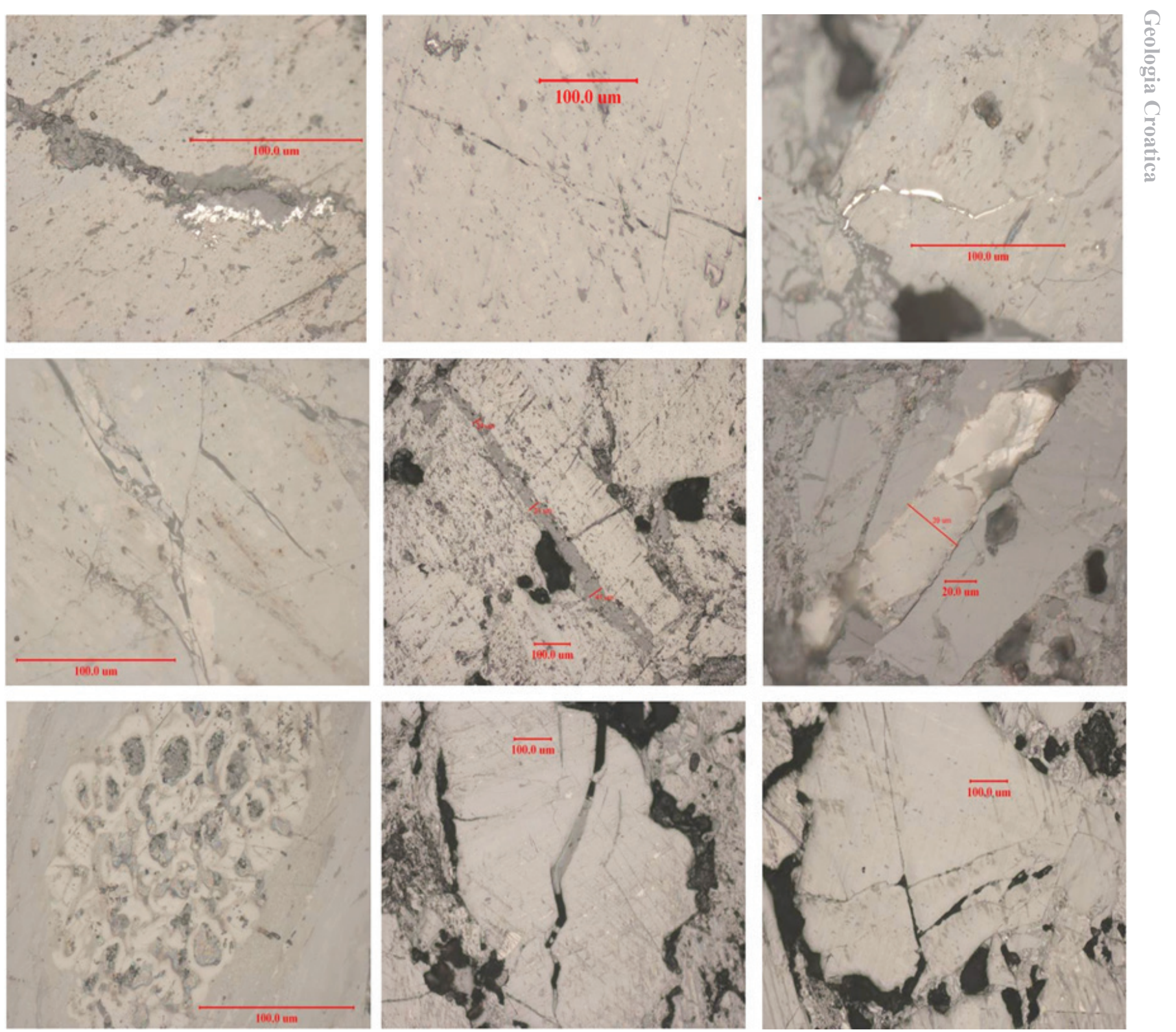

Figure 4. Microfractures in Kuba coalfield.

normal stress is the smallest, which is in accordance with the Mohr-Coulomb failure criterion (YAZDANI BEJARBANEH et al., 2015; HACKSTON \& RUTTER, 2016):

$$
\left|\tau_{f}\right|=\tau_{0+f} \sigma_{\mathrm{n}}
$$

where $\left|\tau_{f}\right|$ is the shear strength of the shearing surface of the rock, $\tau_{0}$ is the inherent shear strength of the rock, which equals the cohesion C. Besides, $f$ and $\phi$ are the internal friction coefficient of the rock and the internal friction angle respectively, $\boldsymbol{f}=\operatorname{tg} \varphi$. In addition, $\sigma_{\mathrm{n}}$ is the normal stress in the shear fracture plane (pressure stress is considered as normal).

In Figure 5. to the right, $\sigma_{1}$ is the maximum principal stress, $\sigma_{3}$ is the minimum principal stress, $\phi$ is the angle between the maximum principal stress and the force that can generate the fractures. The angle between the direction of the outer normal of the shear fracture plane and the maximum principal stress $\sigma_{1}$ :

$$
\alpha=45^{\circ}+\frac{\varphi}{2}
$$

Therefore, the maximum and the minimum stresses respectively bisect the acute angle and the obtuse angle between the two conjugate fracture planes, as shown in Fig. 5.

$$
\begin{gathered}
\sigma_{n}=\frac{1}{2}\left(\sigma_{1}+\sigma_{3}\right)+\frac{1}{2}\left(\sigma_{1}-\sigma_{3}\right) \cos 2 \alpha \\
\left|\tau_{f}\right|=\frac{1}{2}\left(\sigma_{1}-\sigma_{3}\right) \sin 2 \alpha
\end{gathered}
$$

If the above equations are substituted into the Coulomb determination equation, it can be obtained that:

$$
\tau_{0}=-\frac{f}{2}\left(\sigma_{1}+\sigma_{3}\right)-\frac{1}{2}\left(\sigma_{1}-\sigma_{3}\right)(f \cos 2 \alpha-\sin 2 \alpha)
$$

where $\alpha$ is the angle between the normal direction of the shear fracture plane and $\sigma_{1}$, also known as the fracture angle.

Through the transformation equation (5) becomes:

$$
\tau_{0}=\frac{\sigma_{1}}{2}\left[\left(f^{2}+1\right)^{\frac{1}{2}}-f\right]-\frac{\sigma_{3}}{2}\left[\left(f^{2}+1\right)^{\frac{1}{2}}+f\right]
$$






Figure 5. The forces the joint fractures suffer in surrounding rocks.

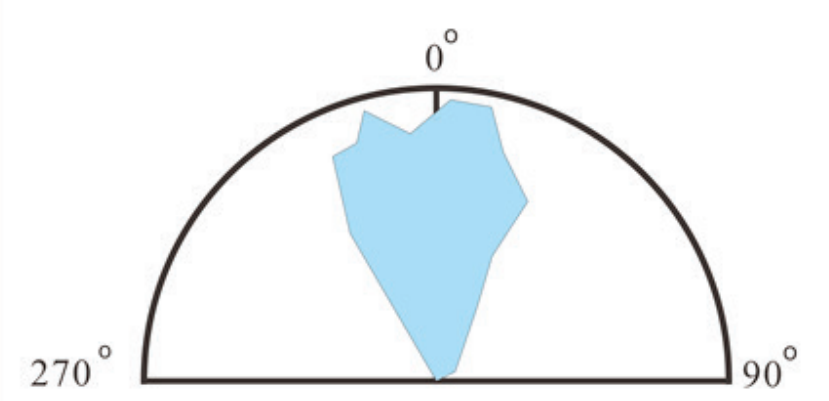

Figure 6. Rose and dip distribution.

Equation (6) is the failure criterion based on $\sigma_{1}$ and $\sigma_{3}$. If the principal stresses $\sigma_{1}$ and $\sigma_{3}$ satisfy this equation, shear fractures are formed.

While conducting the large-scale mapping on the structural fractures in the research area, it was discovered that the structural fractures are developed in all directions of the strata, but are dominated by three directions, namely, NNW-SSE, NNE-SSW, and S-N (Fig. 6. left side). The dip angle of each degree in a rock formation is developed, and there is no dominant direction (Fig. 6 right side).

According to the statistical analysis, it was observed that the degree of fracture development in the research area is closely related to the lithology and the stratum thickness.

\subsection{The lithology of the surrounding rocks and the fracture density}

Based on the mapping of outcropping structural fractures in the field and the fine contrast technique of coal reservoirs in the underground coal mine workings, a total of 4405 joints were measured in the study area. Lithology has a significant influence on the degree of development of the fractures: when the particles and pore volumes of rock are decreased, the fracture generated become compact. When the rock strength increases, even a small strain can give rise to breakage and deformation of the fracture, leading to the widely developed fractures in the rocks with low porosity and fine particles. This research collected the measured

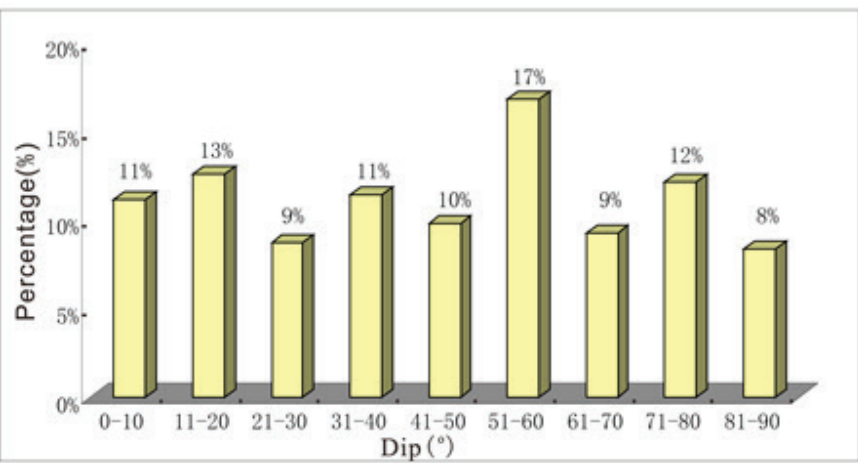

data in different observation points of the research area and selected the strata of different lithologies with the thickness of $20 \mathrm{~cm}$ as the standard. Within these considering the average linear density, 3.6, 4.2, 4.9, 5.3, 6.3, and 8.0 fractures were developed per metre in the fine conglomerate, gritstone, medium sandstone, fine sandstone, and mudstone respectively (Fig. 7). It can be clearly concluded from the graph in Fig. 7 that the finer-grained the rock is, the greater the linear density of the fracture. In contrast, the coarser-grained the rock is, the smaller the linear density of the joint fracture.

\subsection{The thickness of the surrounding rocks and the fracture density}

Joint density varies with the stratum thickness. Generally speaking, when an external force acts on rocks of the same lithology but of different thicknesses, the joints in the thin layers have small distances and great density. Since the strata in the research area are well exposed at outcrop, the development of the tectonic joints at different thicknesses can be observed in most of the observation points.

The linear densities of the fractures developed in different lithologies and the stratum thicknesses in all observation points of the research area were collected, among which, those of gritstone were applied as an example to illustrate the relationship between the stratum thickness and the linear density of the joint fractures. As shown in Figure 8B, an increase in the stratum 


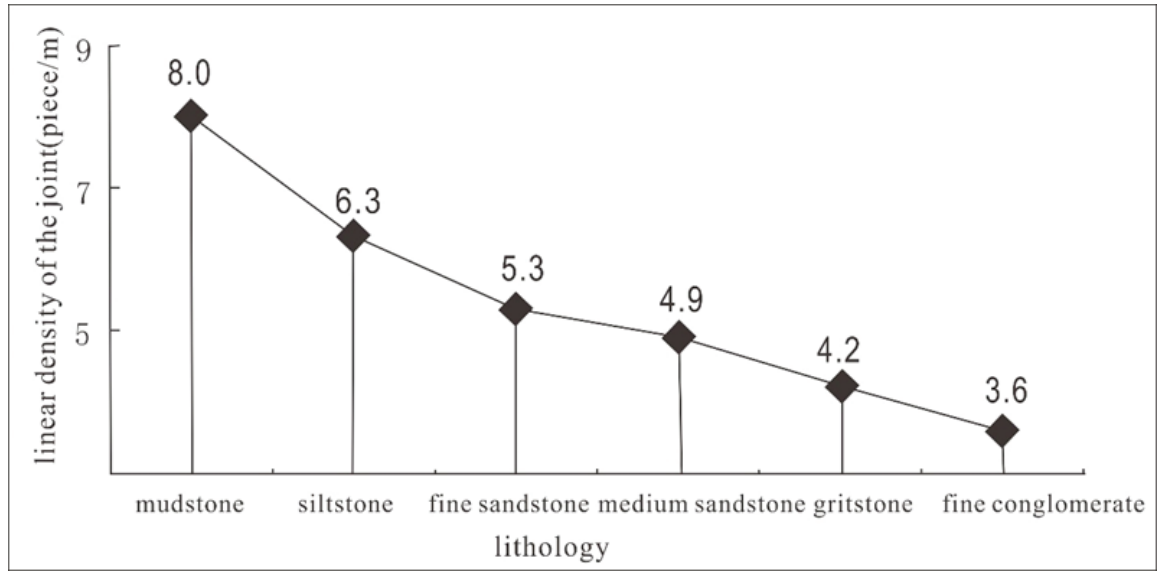

Figure 7. Average linear density of structural fractures.

thickness of the gritstone exhibits an exponential decrease in the linear density of the joint fractures according to the function $\mathrm{y}=$ $33.57 \mathrm{x}^{-0.58}$ and with a correlation coefficient of $\mathrm{R}^{2}=0.73$. In the function, $\mathrm{x}$ represents the stratum thickness $(\mathrm{m})$, and $\mathrm{y}$ is the linear density of the fractures. The latter (fractures per metre) can be expressed as pieces per metre (pieces $/ \mathrm{m}$ ). Meanwhile, a simi- lar relationship was also found in the conglomerate, medium sandstone, fine sandstone, siltstone and mudstone (Figure 8A, C, $\mathrm{D}, \mathrm{E}, \mathrm{F})$. Therefore, with the increase of the stratum thickness, the linear density of the fractures decreases exponentially, when the stratum thickness is more than $1 \mathrm{~m}$, the linear density of the fracture tends to be a fixed value.
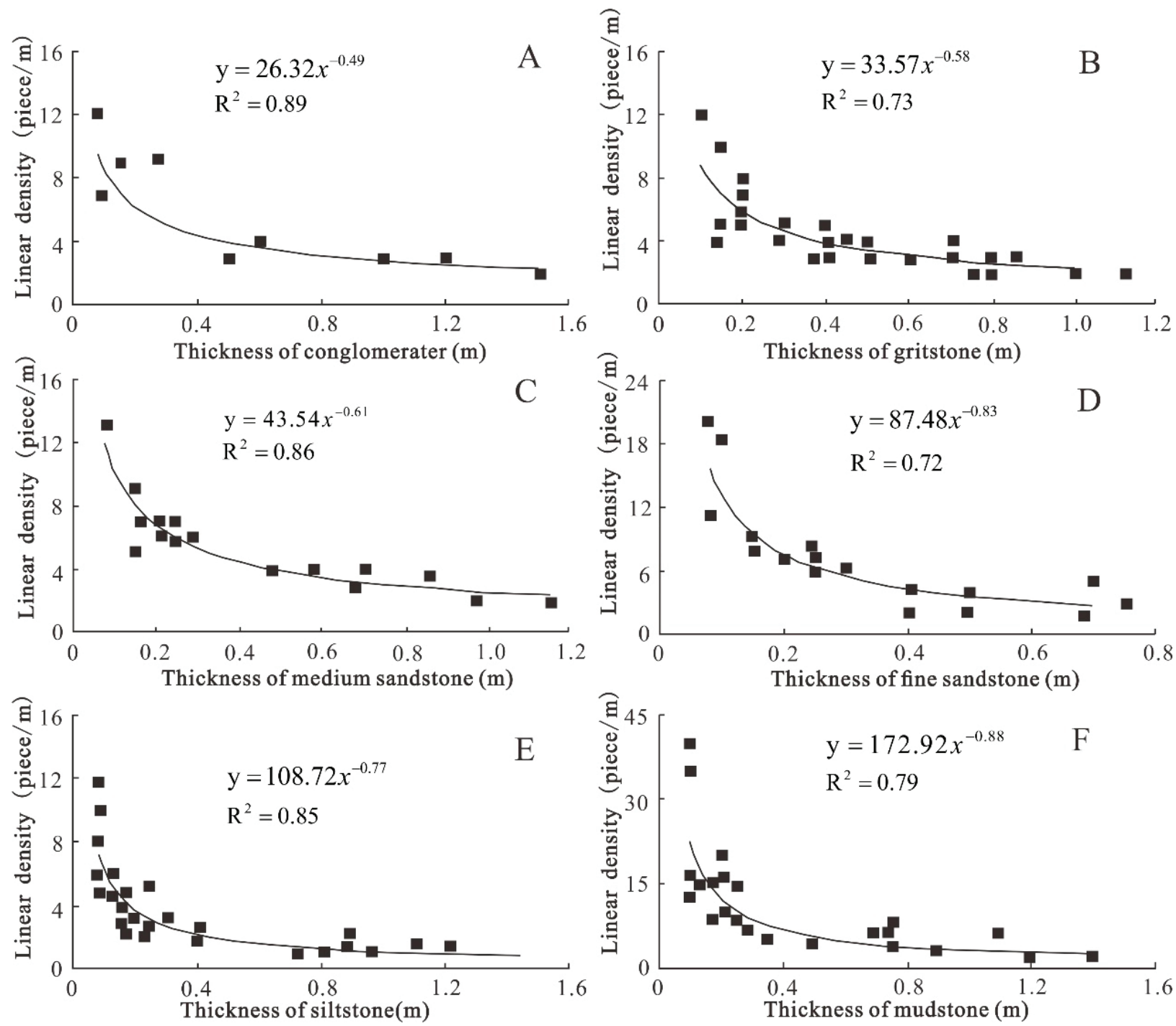

Figure 8. Relationship between the stratum thickness and the linear density of fractures for different lithologies; A: conglomerate; B: gritstone; C: medium sandstone; D: fine sandstone; E: siltstone; F: mudstone. 
The relationship between the stratum thickness of the surrounding rocks and the fracture density:

The conglomerate fitting formula:

$y=26.35 x^{-0.49} R^{2}=0.89$

The gritstone fitting formula:

$y=33.57 x^{-0.58} R^{2}=0.73$

The medium sandstone fitting formula:

$y=43.54 x^{-0.61} R^{2}=0.86$

The fine sandstone fitting formula:

$y=87.48 x^{-0.83} R^{2}=0.72$

The siltstone fitting formula:

$y=108.72 x^{-0.77} R^{2}=0.85$

The mudstone fitting formula:

$y=172.92 x^{-0.88} R^{2}=0.79$

\subsection{The fractures in the coal seam outcrops}

The outcropping of coal in the study area (Figs. 2 and 9) is well preserved and can be used to observe directly the development characteristics of the structural fractures, such as the development of the density of structural fractures and the development directions of the structural fractures. Based on the statistics of a large number of measured data, it was found that the outcropped coal seams $\mathrm{A}_{5}$ and $\mathrm{A}_{7}$ dip towards the $\mathrm{S}$ (azimuth $175^{\circ}$ ) with an inclination angle of $85^{\circ}$. Statistical analysis of endogenous and exogenous fractures in $\mathrm{A}_{5}$ and $\mathrm{A}_{7}$ coal seams was carried out, which can be divided into different types of coal lithotypes, and the thickness, attitude and density of coal layers were counted, as shown Table 1.

The development of the fractures in the coal seam outcrops shows that the density of exogenic fractures of the $A_{5}$ coal seam

Table 1. The development of the fractures in the outcropped coal seams of the research area.

\begin{tabular}{|c|c|c|c|c|c|c|}
\hline \multirow{2}{*}{$\begin{array}{l}\text { Coal } \\
\text { seam }\end{array}$} & \multirow{2}{*}{ Coal lithotypes } & \multirow{2}{*}{$\begin{array}{c}\text { Thickness/ } \\
\mathrm{cm}\end{array}$} & \multicolumn{2}{|c|}{ Exogenetic fractures } & \multicolumn{2}{|c|}{ endogenic fractures } \\
\hline & & & Attitude & Density piece/m & Attitude & Density piece/m \\
\hline \multirow{7}{*}{$\mathrm{A}_{5}$} & semidull coal & 40 & $110^{\circ} \angle 23^{\circ}$ & 10 & & \\
\hline & semibright coal & 10 & & & $266^{\circ} \angle 75^{\circ} 285^{\circ} \angle 5^{\circ}$ & 140120 \\
\hline & semibright coal & 45 & $108^{\circ} \angle 25^{\circ}$ & 6 & $275^{\circ} \angle 79^{\circ} 158^{\circ} \angle 75^{\circ}$ & 160140 \\
\hline & semibright coal & 15 & $118^{\circ} \angle 28^{\circ}$ & 6 & $275^{\circ} \angle 79^{\circ} 158^{\circ} \angle 75^{\circ}$ & 160140 \\
\hline & dirt band & 5 & $118^{\circ} \angle 28^{\circ} 252^{\circ} \angle 46^{\circ}$ & 1010 & & \\
\hline & semibright coal & 25 & $110^{\circ} \angle 23^{\circ}$ & 6 & $275^{\circ} \angle 79^{\circ} 158^{\circ} \angle 75^{\circ}$ & 220180 \\
\hline & bright coal & 60 & $110^{\circ} \angle 23^{\circ}$ & 6 & $275^{\circ} \angle 79^{\circ} 158^{\circ} \angle 75^{\circ}$ & 220180 \\
\hline \multirow{2}{*}{$A_{7}$} & semibright coal & 65 & $105^{\circ} \angle 27^{\circ} 252^{\circ} \angle 46^{\circ}$ & 1413 & $182^{\circ} \angle 85^{\circ} 138^{\circ} \angle 7^{\circ}$ & 22095 \\
\hline & semidull coal & 45 & $100^{\circ} \angle 23^{\circ} 268^{\circ} \angle 73^{\circ}$ & 2520 & $172^{\circ} \angle 88^{\circ}$ & 110 \\
\hline
\end{tabular}
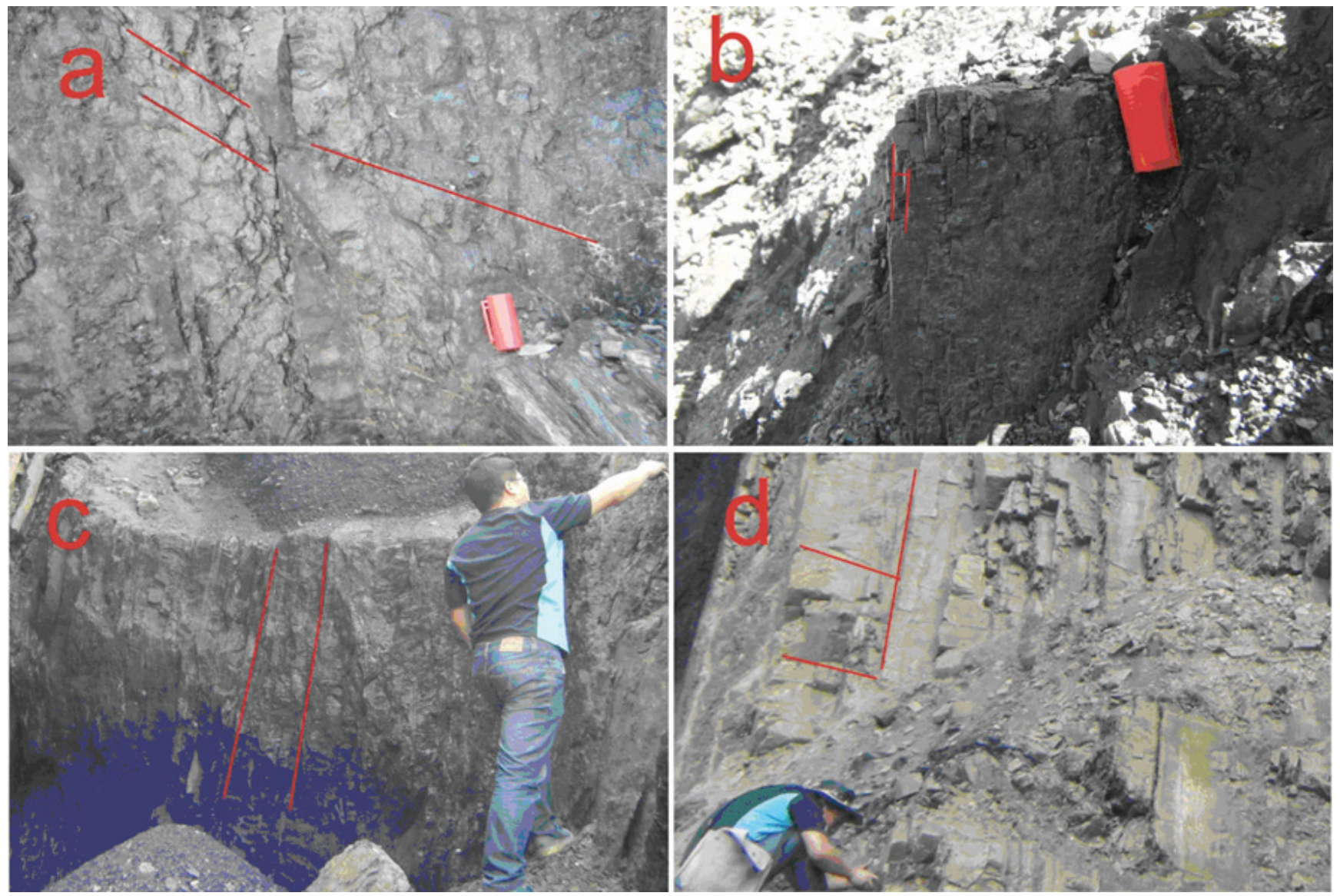

Figure 9. The development of the fractures in the outcropped coal seams of the research area; $a$ : Exogenic fractures of the $A_{5}$ coal seam; $b$ : Endogenic fractures of the $A_{5}$ coal seam; $c$ : Fractures on the surface of the $A_{7}$ coal seam; $d$ : Fractures on the floor of the $A_{7}$ coal seam. 
ranges from $6-10$ pieces $/ \mathrm{m}$, with an average density of 6.8 pieces/m (Table 1). The density of exogenic fractures of the $A_{7}$ coal seam ranges from $13-25$ pieces $/ \mathrm{m}$, while the average density is 18 pieces $/ \mathrm{m}$. Endogenic fracture densities of the $A_{5}$ and $A_{7}$ coal seams ranges from $110-220$ pieces/m, with an average density of $160 \mathrm{pieces} / \mathrm{m}$.

\subsection{The cleats in the coal seam outcrops}

According to the macroscopic coal compositions in separate strata, the development of the exogenic and endogenic fractures in each stratum were measured. In the outcrops of the coal seams $\mathrm{A}_{5}$ and $\mathrm{A}_{7}$, exogenic fractures mainly extend to the NNW-SSE, NNE-SSW and S-N direction. This is coincident with the growth directions of the fractures in the surrounding rocks. The endogenic fractures trend mainly S-N and SW-NE where the lengths of the face cleats and the butt cleats, are $5-15 \mathrm{~cm}$ and $0.5-2 \mathrm{~cm}$, respectively. The face cleats and the butt cleats are perpendicular to bedding and intersect perpendicularly, the face cleats are dominant, while the butt cleats are shorter and connect them (CLOSE, 1993; LAUBACH et al., 1998; GRESLEY, 2009; WENIGER et al., 2016).

The development of the exogenic fractures (joints) in both the surrounding rocks and the coal seams usually ends at a stratum surface, which is called the boundary of the mechanical layers. The height of joints between two boundaries of the mechanical layer is the thickness of the layer, which can either be the thickness of a single stratum or of multiple strata. The exogenic fractures in coal seams are generally developed in the small strata of coal which are petrograpically different by their lithotype composition, varying from dull, semi-dull, semi-bright and bright coal lithotypes. The directions of the fractures of different strata of coal are coincident, as shown in Figure 9(a) and Figure 9(c). As demonstrated in Figure 9(b) and Figure 9(d), the development of the fractures in the surrounding rocks is similar to that in the coal seams. The endogenic fractures are developed adequately in the coal seams of the research area with a maximum linear density of $220 \mathrm{pieces} / \mathrm{m}$.

\subsection{The fractures in the underground coal seams}

The heading face of the $A_{5}$ coal seam was applied as the underground observation point, which is located in the western part of the +2000 horizontal roadway in the Dawanqi coal mine of the Kuba coalfield. The coal seam is buried $210 \mathrm{~m}$ underground with a thickness of $8.2 \mathrm{~m}$, in which $3.1 \mathrm{~m}$ of coal could be observed (Figure 10).

The $A_{5}$ coal seam is inclined southward with a dip angle of $83^{\circ}$ (Fig. 10). The coal is mainly fragmented but undeformed. It exhibits an integral coal structure. The linear density and the length of the endogenic fractures are 200 pieces $/ \mathrm{m}$, respectively, while the occurrence is divided into two groups, namely, the group with a dip of $273^{\circ} / 83^{\circ}$, and $232^{\circ} / 41^{\circ}$. Exogenic fractures can be divided into four groups. The exogenic joints are dip to $271^{\circ}$ and $115^{\circ}$ with inclinations of $86^{\circ}$ and $44^{\circ}$ with a linear density of 2-4 pieces $/ \mathrm{m}$. These exogenic joints are characterized by their preferable extensibility, regular development, and almost complete extent through the visual area. Exogenic joints with a dip of $20^{\circ} / 30^{\circ}$, are slightly deformed with the linear density reaching 6 pieces $/ \mathrm{m}$. In addition, a few joints are developed in the group with a dip of $90^{\circ} / 65^{\circ}$ (Figure 10).

The observed thickness of the $A_{7}$ coal seam underground is about $2 \mathrm{~m}$, and the roof and the floor are both visible. The roof and the floor are composed of the glutenites and the grey-black mudstones respectively, and the coal is a dark black colour. In macro level, the coal rock is half-duration, which has an integral coal structure and is composed of the fragmented coal of primary structure. Three groups of regularly developed exogenic joints are inclined to $281^{\circ}, 273^{\circ}$, and $41^{\circ}$ with dip angles of $35^{\circ}, 54^{\circ}$, and $60^{\circ}$ respectively. There is one group of endogenic fractures, which are inclined to $221^{\circ}$ with a dip angle of $60^{\circ}$ and a linear density of 10 pieces/m (Figure 11).

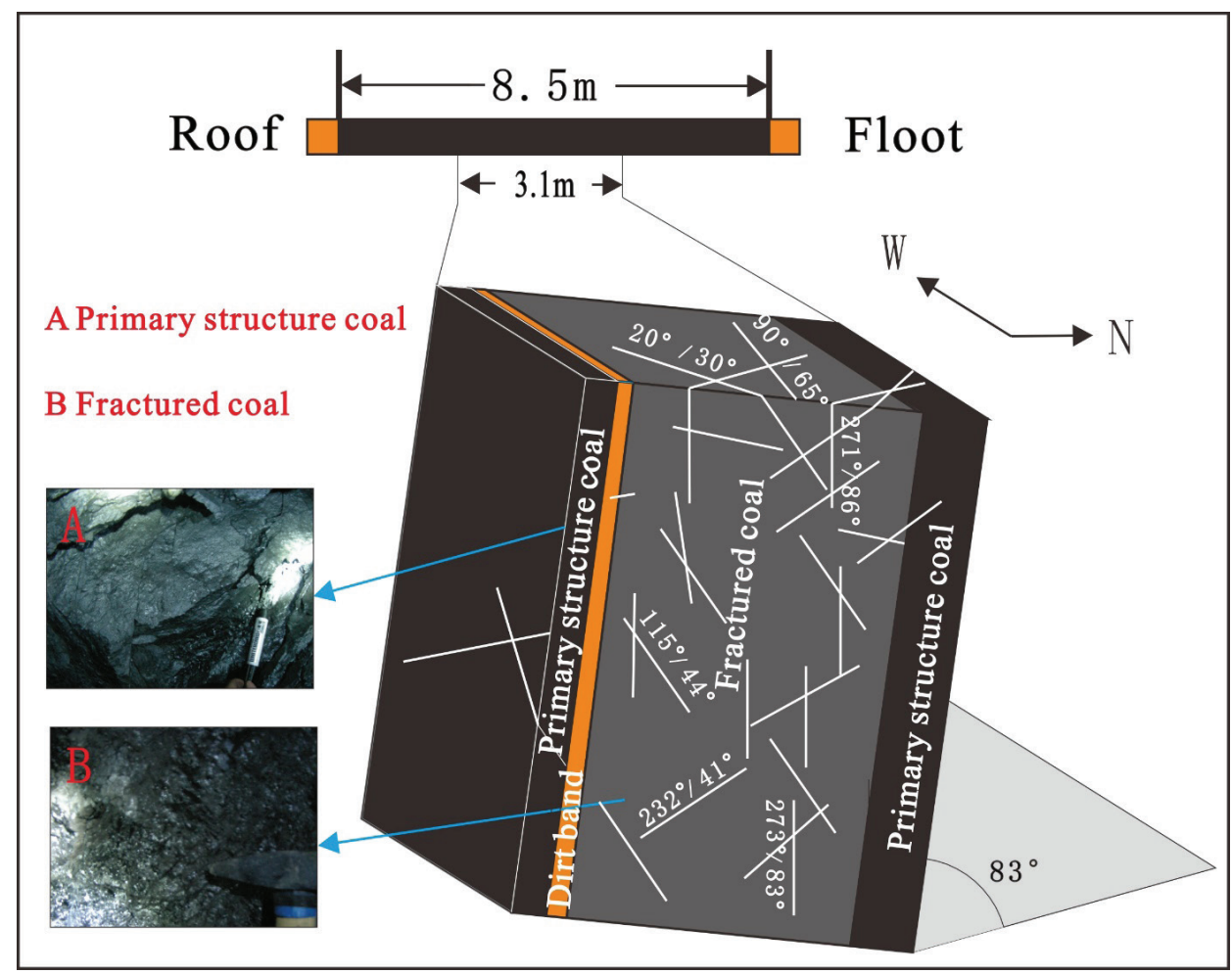

Figure 10. Observation Map of Coal body structure in $A_{5}$ coal seam. 


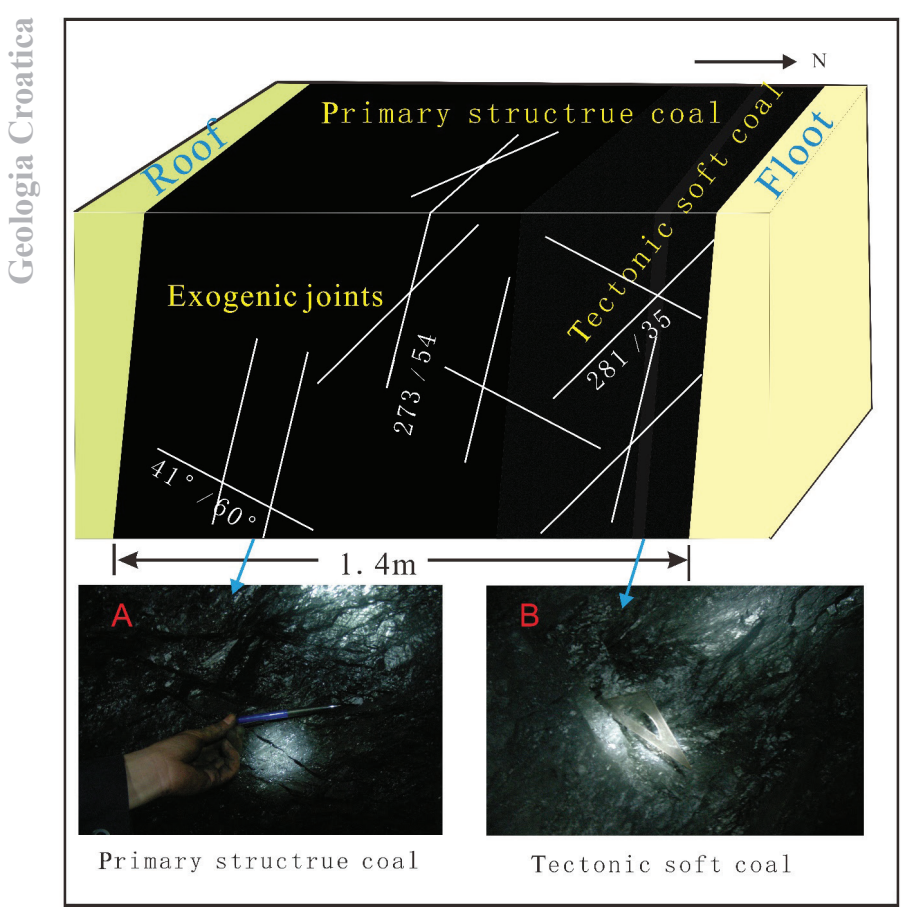

Figure 11. Observation Map of Coal body structure in $A_{7}$ coal seam.

According to the observed results from the underground, the fractures in the coal seams extend N-S and NNE-SSW, with few trending NNW-SSE, which is basically coincident with the results observed at the surface. According to the analysis, fractures with the same direction are found in the surrounding rocks and the coal seams on the ground, as well as in the roof, floor and seams of the underground coal seams. Therefore, it verifies that when the coal seam and the surrounding rock of the same tectonic layer suffer from the same tectonic stress, the joint fractures generated in them are similar.

\subsection{Measured section}

The middle part coal mine of the Kuba coalfield is characterized by approximately vertical coal seams and surrounding rocks, as well as the well-preserved coal seam outcrops at the surface. Therefore, it provides excellent conditions for observing and analyzing the corresponding relationship between the fracture systems in the coal seams and the surrounding rocks. Besides, the corresponding relationship of the fracture development in the coal seams and the surrounding rocks can be established visually by analyzing multiple sections.

Multiple sections were measured in the research area. The primary mineable coal seams of $\mathrm{A}_{5}$ and $\mathrm{A}_{7}$ and their roofs and floors outcropped in these sections, which provides favourable conditions for investigating the corresponding relationship between the fractures in the coal seams and the surrounding rocks. Taking one section for example, relevant data are illustrated in Figure 12. and Table 2.

One section that contains the primary mineable coal seams of $\mathrm{A}_{5}$ and $\mathrm{A}_{7}$, mudstone, siltstone, fine sandstone, medium sandstone, gritstone, and fine conglomerate was measured. By measuring the attitude and linear density of the structural fractures as well as the thickness of each stratum, the corresponding relationship between the exogenous fractures in the coal mines and the surrounding rocks can be visually observed. As shown in Table 2 , multiple groups of joints are developed in each stratum, and only the occurrences of the fractures in the dominated directions are illustrated.

Figure 13. shows that the thickness of strata in the measured section is inversely proportional to the density of structural fractures, that is, with the increase in the thickness of strata, the density of structural fractures decreases. This relationship exists in coal seams, fine conglomerate, medium sandstone, siltstone, and mudstone, and is consistent with the previous mapping results.

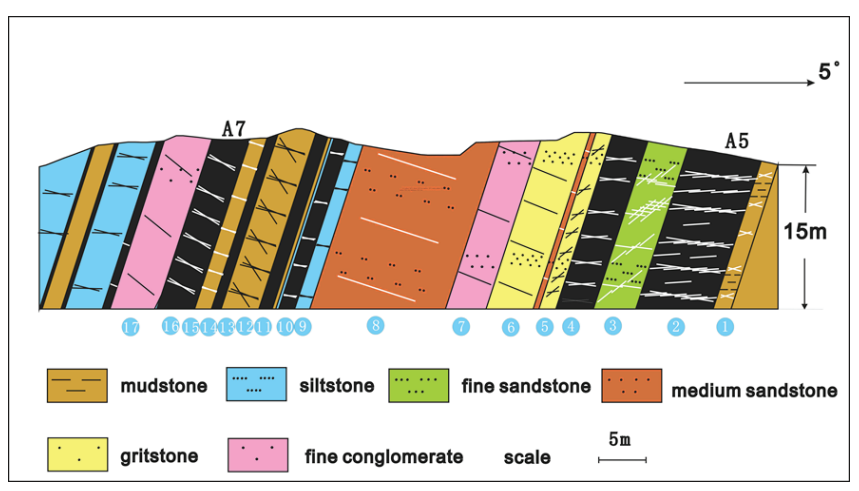

Figure 12. Measured section in the research area.

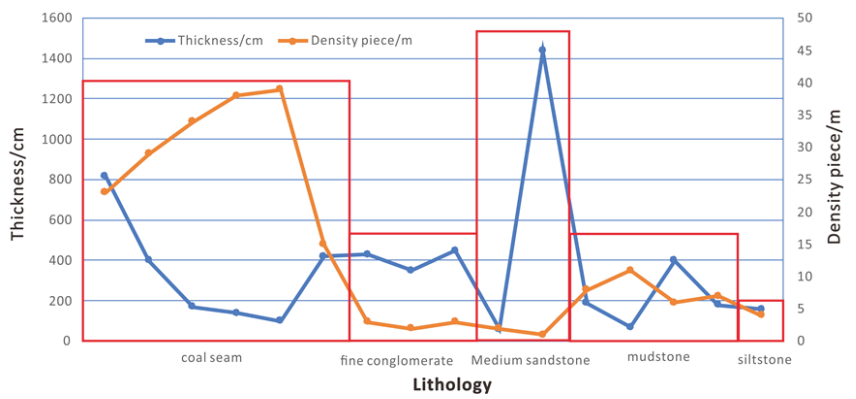

Figure 13. The relation between thickness and density of measured section.

Table 2. The measured section data statistics.

\begin{tabular}{|c|c|c|c|c|c|c|c|c|c|}
\hline Number & Lithology & $\begin{array}{c}\text { Thickness/ } \\
\text { cm }\end{array}$ & $\begin{array}{c}\text { Dominant direction } \\
\text { of attitude }\end{array}$ & $\begin{array}{l}\text { Density } \\
\text { piece/m }\end{array}$ & Number & Lithology & $\begin{array}{c}\text { Thickness/ } \\
\text { cm }\end{array}$ & $\begin{array}{c}\text { Dominant direction } \\
\text { of attitude }\end{array}$ & $\begin{array}{l}\text { Density } \\
\text { piece/m }\end{array}$ \\
\hline 1 & mudstone & 190 & $280^{\circ} \angle 55^{\circ}$ & 8 & 10 & coal seam & 170 & $272^{\circ} \angle 48^{\circ}$ & 34 \\
\hline 2 & coal seam & 820 & $287^{\circ} \angle 44^{\circ}$ & 23 & 11 & mudstone & 70 & $278^{\circ} \angle 45^{\circ}$ & 11 \\
\hline 3 & Fine sandstone & 450 & $294^{\circ} \angle 47^{\circ}$ & 3 & 12 & coal seam & 140 & $271^{\circ} \angle 40^{\circ}$ & 38 \\
\hline 4 & coal seam & 400 & $281^{\circ} \angle 52^{\circ}$ & 29 & 13 & mudstone & 400 & $275^{\circ} \angle 80^{\circ}$ & 6 \\
\hline 5 & Medium sandstone & 60 & $307^{\circ} \angle 21^{\circ}$ & 2 & 14 & coal seam & 100 & $278^{\circ} \angle 68^{\circ}$ & 39 \\
\hline 6 & gritstone & 500 & $300^{\circ} \angle 20^{\circ}$ & 4 & 15 & mudstone & 180 & $273^{\circ} \angle 65^{\circ}$ & 7 \\
\hline 7 & fine conglomerate & 430 & $305^{\circ} \angle 40^{\circ}$ & 3 & 16 & coal seam & 420 & $273^{\circ} \angle 54^{\circ}$ & 15 \\
\hline 8 & Medium sandstone & 1440 & $304^{\circ} \angle 35^{\circ}$ & 1 & 17 & Fine conglomerate & 350 & $301^{\circ} \angle 35^{\circ}$ & 2 \\
\hline 9 & siltstone & 160 & $276^{\circ} \angle 54^{\circ}$ & 4 & & & & & \\
\hline
\end{tabular}




\subsection{The direction of the fractures in the coal seams and the surrounding rocks}

As observed in the measured data, the dominant direction of the fractures in the coal seams is basically in accordance with that in the surrounding rocks. The occurrences of the dominant fractures in mudstone, siltstone, and fine sandstone are coincident with those in the coal seams, with a mere $10^{\circ}$ variance in orientation. Despite the dominant joints in medium sandstone, gritstone and fine conglomerate presenting the same occurrence, the occurrence differs about $20^{\circ}$ from that in the coal seams considering the dominant direction, to even more than $30^{\circ}$ in some strata. Therefore, the direction of the structural fractures in the coal seams can be predicted accurately by investigating the fractures developed in mudstone and siltstone. The structural fractures developed in the coal seams are mainly trended to NNE-SSW and $\mathrm{N}-\mathrm{S}$ directions.

\subsection{The corresponding relationship concerning the degree of fracture development}

The linear density of fractures developed in strata (coal seams) is a key parameter for predicting the fragmentation of the coal structure. Owing to fractures in different directions being found in one observation point, the sum of the fractures developed within the circle with a radius for $2 \mathrm{~m}$ was applied as the number of fractures at a particular observation point. Afterward, the relationship between the stratum thickness and the linear density of fractures in the different lithologies was established by investigating the data of all the observation points in the research area.

The relationship between rock thickness and density has been described, as in formulae (7)-(12).

The relationship between the stratum thickness of the coal rocks and the fracture density can be exppressed as:

$$
\begin{gathered}
\text { The coal seam fitting formula: } \\
y=645.74 x^{-0.33} R^{2}=0.85
\end{gathered}
$$

In the formulae from (7)-(12), $x$ represents the stratum thickness of each lithology in $\mathrm{cm}$, $y$ indicates the linear density of the fractures in different lithologies (pieces $/ \mathrm{m}$ ). The aforementioned formulae demonstrate that the linear density of fractures is merely related to the stratum thickness. Meanwhile, since small tectonics such as faults and folds are not developed in the research area, the development of the fractures located in different tectonic structures is ignored here. Therefore, the established corresponding relationship between the linear density of the fractures in the coal seam and the lithology is given as follows:

When the thickness of the mudstone is the same as that of the coal seams, we obtain, $\mathrm{y}_{\text {coal }}=645.74 \mathrm{x}_{\text {coal }}{ }^{-0.33}$ and $\mathrm{y}_{\text {mud }}=$ $172.92 \mathrm{x}_{\text {coal }}{ }^{-0.88}$, namely, $\mathrm{y}_{\text {coal }} / \mathrm{y}_{\text {mud }}=645.74 \mathrm{x}_{\text {coal }}{ }^{-0.33} / 172.92 \mathrm{x}_{\text {coal }}{ }^{-0.88}$

Therefore, the following relationships can be obtained:
The corresponding relationship between the fractures in the mudstone and the coal seams:

$$
\mathrm{y}_{\text {coal }}=645.74 \mathrm{x}_{\text {coal }}{ }^{0.55} \mathrm{x}_{\text {mud }}{ }^{-0.88}
$$

The corresponding relationship between the fractures in the siltstone and the coal seams:

$$
\mathrm{y}_{\text {coal }}=645.74 \mathrm{x}_{\text {coal }}{ }^{0.44} \mathrm{x}_{\text {silt }}{ }^{-0.77}
$$

The corresponding relationship between the fractures in the fine sandstone and the coal seams:

$$
\mathrm{y}_{\text {coal }}=645.74 \mathrm{x}_{\text {coal }}{ }^{0.50} \mathrm{x}_{\text {fine }}{ }^{-0.83}
$$

The corresponding relationship between the fractures in the medium sandstone and the coal seams:

$$
\mathrm{y}_{\text {coal }}=645.74 \mathrm{x}_{\text {coal }}{ }^{0.28} \mathrm{x}_{\text {med }}{ }^{-0.61}
$$

The corresponding relationship between the fractures in the gritstone and the coal seams:

$$
\mathrm{y}_{\text {coal }}=645.74 \mathrm{x}_{\text {coal }}{ }^{0.25} \mathrm{x}_{\text {grit }}{ }^{-0.58}
$$

The corresponding relationship between the fractures in the conglomerate and the coal seams:

$$
\mathrm{y}_{\text {coal }}=645.74 \mathrm{x}_{\text {coal }}{ }^{0.16} \mathrm{x}_{\text {con }}{ }^{-0.49}
$$

Formulae (13)-(19) exhibit the corresponding relationship between the fractures in the coal seams and other strata in the research area. Therefore, $\mathrm{y}_{\text {coal }}$ represents the linear density of the fractures in the coal seams (piece $/ \mathrm{m}$ ). $\mathrm{x}_{\text {coal }}$ indicates the thickness of the underground coal seam corresponding to the observation point on the ground (m), which can be calculated through the contour map of the coal seam thickness. $\mathrm{x}_{\text {silt (etc.) }}$ denotes the thickness of different strata observed at the observation point on the ground (m).

By substituting the data measured in the field into the formulae (13)-(19), the linear density of the fractures in the underground coal seams can be calculated, which can be utilized to divide the degree of fracture development in coal seams.

\subsection{The prediction of fracture development in the coal seams}

By studying the surface outcrop of the approximately vertical coal seams and the exposed underground seams in the research area, the development range of the linear density of the fractures in the undeformed coal and the fragmentized coal, from which CBM can be explored, was determined visually and quantitatively. After calculating the linear density of the fractures in the coal seams of the research area using the formulae (13)-(19), the research area was divided into zones with dense, moderate and un-developed fractures.

The zones with dense fractures present a high density of the joint fractures and destroyed coal structure in the coal seam, which therefore is endowed with poor stability. The correspond-

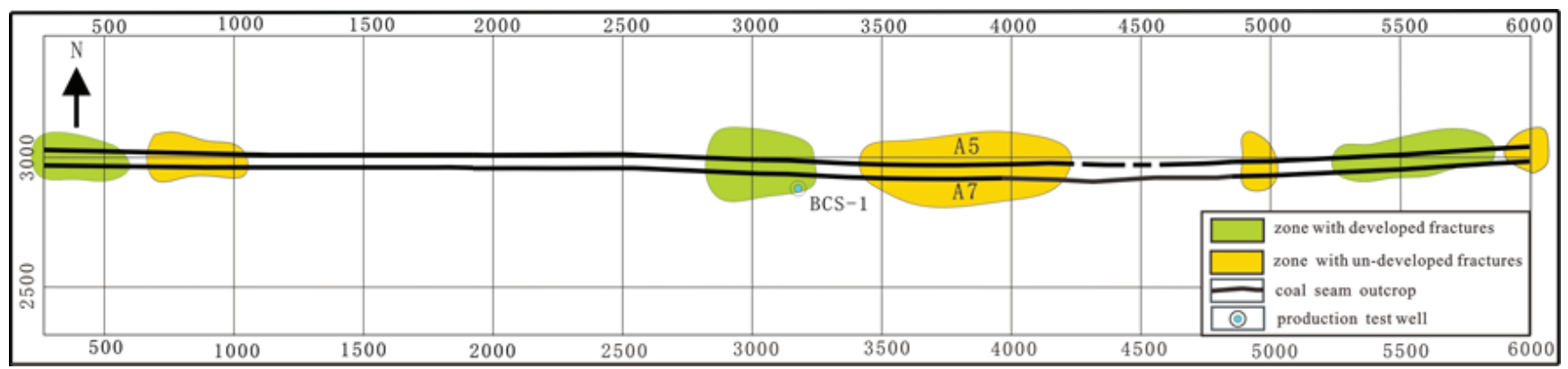

Figure 14. The prediction of the fracture development in the research area. 
ing coal structures are the fragmented coal and mylonitic coal. Since the over-developed exogenic fractures are expected to destroy the seal of the coal seams, these type of zones should not be considered in the exploration and development of CBM.

In the zones with moderate fractures, the fracture density is medium compared with those of the dense zone and the un-developed zone with an integral and stable coal structure. Correspondingly, fragmented coal is found in this category of zone. Meanwhile, the endogenic fractures of the coal seam are interlinked by the exogenic fractures, therefore improving the permeability of the coal seam.

The zones with un-developed fractures are characterized by a low fracture density, an integral and stable coal structure which is the undeformed coal. Given that the exogenic fractures are not developed in the coal seams, the permeability of the coal seam is therefore barely improved, which poses no threat to the storage of CBM (Figure 14).

By analyzing the corresponding relationship between the growth directions of the fractures in the coal seams and the surrounding rocks, the growth direction of dominant fractures in the research area can be determined, which is also the direction of the principal permeability of the coal seam. Therefore, the growth direction of the main fractures is required to be considered while determining the well pattern, good drilling locations and well spacing.

\section{CONCLUSIONS}

Large-scale mapping of the structural fractures on the ground and the technology for finely and comparatively analyzing the sections of underground coal seams were applied when studying the approximately vertical coal seams of the Kuba coalfield in Xinjiang, China. Meanwhile, a new method was put forward for predicting the fractures in coal seams and the coal structure.

(1) The corresponding relationship between the development characteristics including the direction and degree of fracture development in the coal seams and the surrounding rocks was established in the Kuba coalfield of Xinjiang. The research predicted the development characteristics of the fractures in the coal seams of the research area and divided the area into zones with dense, moderate and un-developed fractures. It should be noted that this method is applicable to areas where the surrounding rock and coal seam belong to the same tectonic layer and the surrounding rock is exposed at the surface.

(2) Studies regarding the corresponding relationship between the fractures in coal seams and the surrounding rocks can be employed to predict the fractures in coal seams and the coal structure and arrange a good pattern for the exploration and development of CBM.

\section{ACKNOWLEDGMENT}

This study was financially supported by the National oil and gas major projects, Grant Number 2017ZX05064-002, National Science Foundation of China, Grant Number 41872147; PHD Foundation of Henan Polytechnic University, Grant Number B201766 . We have found lots of useful guidelines in the comments that improved our manuscript.

\section{REFERENCES}

ARLEGUI, L. \& SIMON, J.L. (2001): Geometry and distribution of regional joint sets in a non-homogeneous stress field: case study in the Ebro basin (Spain).- Journal of Structural Geology, 23/2-3, 297-313. doi: 10.1016/S0191-8141(00)00097-3

AYERS, W.B. (2002): Coalbed gas systems, resources, and production and a review of contrasting cases from the San Juan and Powder River basins.- American Association of Petroleum Geologists Bulletin, 86, 1853-1890.
BAI, T. \& POLLARD, D.D. (2000): Fracture spacing in layered rocks: a new explanation based on the stress transition.- Journal of Structural Geology, 22/1, 43-57. doi: 10.1016/S0191-8141(99)00137-6

BROOK, M.S., HEBBLEWHITE, B.W. \& MITRA, R. (2016): Cleat aperture-size distributions: A case study from the Late Permian Rangal Coal Measures, Bowen Basin, Australia.- International Journal of Coal Geology, 168, 186-192. doi:10.1016/j.coal.2016.11.009.

BUSSE, J., DE DREUZY, J.R., GALINDO TORRES, S., BRINGEMEIER, D. \& SCHEUERMANN, A. (2017): Image processing based characterisation of coal cleat networks.- International Journal of Coal Geology, 169, 1-21. doi:10.1016/j. coal.2016.11.010.

CHEN, S., TANG, D., TAO, S., XU, H., LI, S., ZHAO, J., REN, P. \& FU, H. (2017): Insitu stress measurements and stress distribution characteristics of coal reservoirs in major coalfields in China: Implication for coalbed methane (CBM) development.- International Journal of Coal Geology, 182, 66-84. doi:10.1016/j. coal.2017.09.009

CLOSE, J.C. (1993): Natural Fractures in Coal-- American Association of Petroleum Geologists Bulletin, 38, 119-132.

DATTA, D.R. (2016): Coal, Cleat System.- Encyclopedia of Mineral and Energy Policy, $1-4$.

DAWSON, G.K.W. \& ESTERLE, J.S. (2010): Controls on coal cleat spacing.- International Journal of Coal Geology, 82, 213-218. doi:10.1016/j.coal.2009.10.004

FENG, J., REN, Q. \& XU, K. (2018): Quantitative prediction of fracture distribution using geomechanical method within Kuqa Depression, Tarim Basin, NW China.Journal of Petroleum Science and Engineering, 162, 22-34. doi:10.1016/j.petrol.2017.12.006.

GRESLEY, W.S. (2009): Theory for "Cleat" in Coal-Seams.- Geological Magazine, 9, doi:10.1017/s0016756800196074.

HACKSTON, A. \& RUTTER, E. (2016): The Mohr-Coulomb criterion for intact rock strength and friction - a re-evaluation and consideration of failure under polyaxial stresses.- Solid Earth, 7, 493-508. doi:10.5194/se-7-493-2016.

KARACAN, C.O. \& OKANDAN, E. (2000): Fracture/cleat analysis of coal from Zonguldak Basin (northwestern Turkey) relative to the potential of coalbed methane production.- Int. Journal of Coal Geology, 44, 109-125. doi: 10.1016/S01665162(00)00004-5

KORONCZ, P.J., PéTER, Á., LEMBERKOVICS, V. \& FEDOR, F. (2017): Pore characterization, acoustic and permeability measurements on core plug triplets, from the Miocene Tótkomlós (Calcareous Marl) Formation of the Pannonian-basin, Hungary.- Geologia Croatica, 70, 87-92. doi:10.4154/gc.2017.09.

LAI, J., LI, D., WANG, G., XIAO, C., HAO, X., LUO, Q., LAI, L. \& QIN, Z. (2019): Earth stress and reservoir quality evaluation in high and steep structure: The Lower Cretaceous in the Kuqa Depression, Tarim Basin, China.- Marine and Petroleum Geology, 101, 43-54. doi:10.1016/j.marpetgeo.2018.11.036.

LAUBACH, S.E., MARRETT, R.A., OLSON, J.E. \& SCOTT, A.R. (1998): Characteristics and origins of coal cleat: A review.- International Journal of Coal Geology, 35, 175-207. doi: 10.1016/S0166-5162(97)00012-8

LI, S., TANG, D., PAN, Z., XU, H. \& HUANG, W. (2013): Characterization of the stress sensitivity of pores for different rank coals by nuclear magnetic resonance.-Fuel, 111, 746-754. doi:10.1016/j.fuel.2013.05.003.

LIANG, D., ZHANG, S., CHEN, J., WANG, F. \& WANG, P. (2003): Organic geochemistry of oil and gas in the Kuqa depression, Tarim Basin, NW China.- Organic Geochemistry, 34, 873-888. doi:10.1016/s0146-6380(03)00029-9.

MCKEE, C.R., C, B.A. \& A, K.R. (1988): Stress-dependent permeability and porosity of coal and other geologic formations,- Spe Production \& Operations, 3, 81-91.

MOORE, T.A. (2012): Coalbed methane: A review.- International Journal of Coal Geology, 101, 36-81. doi:10.1016/j.coal.2012.05.011.

MOSTAGHIMI, P., ARMSTRONG, R.T., GERAMI, A., HU, Y., JING, Y., KAMALI, F., LIU, M., LIU, Z., LU, X., RAMANDI, H.L., ZAMANI, A. \& ZHANG, Y. (2017): Cleat-scale characterisation of coal: An overview.- Journal of Natural Gas Science and Engineering, 39, 143-160. doi:10.1016/j.jngse.2017.01.025.

PASHIN, J.C. \& GROSHONG, J.R.H. (1998): Structural control of coalbed methane production in Alabama.- International Journal of Coal Geology, 38, 89-113. doi: 10.1016/S0166-5162(98)00034-2

RAWNSLEY, K.D., PEACOCK, D.C.P. \& RIVES, T. (1998): Joints in the Mesozoic sediments around the Bristol Channel Basin.- Journal of Structural Geology, 20, 1641-1661. doi: 10.1016/S0191-8141(98)00070-4

SOLANO-ACOSTA, W., MASTALERZ, M. \& SCHIMMELMANN, A. (2007): Cleats and their relation to geologic lineaments and coalbed methane potential in Pennsylvanian coals in Indiana.- International Journal of Coal Geology, 72, 187-208. doi:10.1016/j.coal.2007.02.004.

WENIGER, S., WENIGER, P. \& LITTKE, R. (2016): Characterizing coal cleats from optical measurements for CBM evaluation.- International Journal of Coal Geology, 154-155, 176-192. doi:10.1016/j.coal.2015.12.005.

WHEELER, R.L. (1980): Cross-strike structural discontinuities: possible exploration tool for natural gas in Appalachian overthrust belt.-American Association of Petroleum Geologists Bulletin, 64, 2166-2178. 
WIDERA, M. (2014): What are cleats? Preliminary studies from the Konin lignite mine, Miocene of central Poland.- Geologos, 20, 3-12. doi:10.2478/logos-2014-0001.

YAO, Y., LIU, D., TANG, D., TANG, S., HUANG, W., LIU, Z. \& CHE, Y. (2009): Fractal characterization of seepage-pores of coals from China: An investigation on permeability of coals.- Computers \& Geosciences, 35, 1159-1166. doi:10.1016/j. cageo.2008.09.005.

YAZDANI BEJARBANEH, B., JAHED ARMAGHANI, D. \& MOHD AMIN, M.F. (2015): Strength characterisation of shale using Mohr-Coulomb and Hoek-
Brown criteria.- Measurement, 63, 269-281. doi:10.1016/j.measurement.2014.12.029.

ZHANG, R., LIU, S. \& WANG, Y. (2017): Fractal evolution under in situ pressure and sorption conditions for coal and shale.- Sci Rep, 7, 8971. doi:10.1038/s41598-01709324-9.

ZHAO, J., TANG, D., LIN, W., QIN, Y. \& XU, H. (2019): In-situ stress distribution and its influence on the coal reservoir permeability in the Hancheng area, eastern margin of the Ordos Basin, China.- Journal of Natural Gas Science and Engineering, 61, 119-132. doi:10.1016/j.jngse.2018.09.002. 